\title{
Dilemas morais da gestão pública brasileira no enfrentamento da pandemia do novo coronavírus
}

\author{
Laís Silveira Santos 1
}

1 Universidade Federal de Santa Catarina, Florianópolis / SC - Brasil

\begin{abstract}
Devido à pandemia do novo coronavírus, a gestão pública brasileira tem tomado decisões de interesse público que impactam diretamente a vida de praticamente todos os brasileiros e apresentam diversas questões éticas intrínsecas. Diante deste contexto, este short paper tem como objetivo identificar e debater alguns dos principais dilemas morais que desafiam a gestão pública brasileira no enfrentamento da pandemia. Para tanto, foram selecionadas notícias de websites jornalísticos que apresentassem situações éticas que ocorreram ou ainda estão ocorrendo no Brasil. Seis áreas temáticas com dilemas foram identificadas: distanciamento social; uso de big data no gerenciamento da pandemia; atuação dos profissionais de saúde; auxílio emergencial federal e burocracia; suspensão de aulas e atividades educacionais presenciais; e liberação de presidiários como medida de prevenção. Percebeu-se que, em contextos de crise, cidadãos e gestores públicos são afastados de seu status quo, o que leva a que novas formas de raciocínio moral sejam desenvolvidas. Essas questões demandam uma contínua reflexão e debate sobre os aspectos éticos da pandemia, principalmente em relação às obrigações sociais e morais dos governos e aos limites dessa interferência no direito individual dos cidadãos em um período de crise.
\end{abstract}

Palavras-chave: COVID-19; dilema moral; gestão pública.

\section{Dilemas morales de la gestión pública brasileña en el afrontamiento de la pandemia del nuevo coronavirus}

Debido a la pandemia del nuevo coronavirus, la administración pública brasileña ha tomado decisiones de interés público que afectan directamente la vida de prácticamente todos los brasileños y presentan varios problemas éticos intrínsecos. Ante este contexto, este breve documento tiene como objetivo identificar y discutir algunos de los principales dilemas morales que desafían a la administración pública brasileña en el afrontamiento de la pandemia. Para ello, se seleccionaron noticias de sitios web periodísticos que presentaban situaciones éticas que ocurrieron o aún ocurren en Brasil. Se identificaron seis áreas temáticas con dilemas: distanciamiento social; uso de big data en el manejo de la pandemia; desempeño de los profesionales de salud; ayuda federal de emergencia y burocracia; suspensión de clases y actividades educativas presenciales; y la liberación de prisioneros como medida preventiva. Se observó que, en contextos de crisis, los ciudadanos y los administradores públicos son sacados de su status quo, lo que hace que se desarrollen nuevas formas de razonamiento moral. Estas cuestiones exigen una reflexión y un debate continuos sobre los aspectos éticos de la pandemia, especialmente en relación con las obligaciones sociales y morales de los gobiernos y los límites de las interferencias en el derecho individual de los ciudadanos en un período de crisis. Palabras clave: COVID-19; dilema moral; gestión pública.

\section{Moral dilemmas of the Brazilian public management in the face of the COVID-19 pandemic}

Due to the pandemic of the new coronavirus, Brazilian public management has made decisions of public interest that directly impact the lives of practically all Brazilians and present several intrinsic ethical issues. From this context, this article aims to identify and discuss some of the main moral dilemmas that challenge Brazilian public management in the face of the pandemic. To this end, news reports were selected from journalistic websites that presented dilemmas that occurred or are still occurring in Brazil. Six thematic areas were identified: social distancing; use of big data in the pandemic's management; the performance of health professionals; federal emergency aid and bureaucracy; school closures and online learning; and release of prisoners as a preventive measure. It was observed that, in contexts of crisis, citizens and public managers are displaced from their status quo, which leads to new forms of moral reasoning. These issues demand continuous reflection and debate on the ethical aspects of the pandemic, especially to the governments' social and moral obligations and the limits of such disruption to citizen's rights in a period of crisis.

Keywords: COVID-19; moral dilemma; public management. 


\section{INTRODUÇÃO}

Em janeiro de 2020, a Organização Mundial da Saúde (OMS) iniciou as discussões sobre a formação de uma situação de Emergência de Saúde Pública de Âmbito Internacional em razão do surgimento de um novo coronavírus, na China, em dezembro do ano anterior. Já em 11 de março de 2020, a COVID-19, doença causada pelo vírus, foi declarada pela OMS como "pandêmica", isto é, registrava-se a epidemia de uma doença infecciosa. No Brasil, o primeiro caso da COVID-19 foi registrado em 26 de fevereiro de 2020. Em junho do mesmo ano, o país já somava 600 mil casos confirmados e mais de 33 mil mortes, além dos casos assintomáticos e não notificados (Ministério da Saúde do Brasil, 2020).

Por se tratar de uma situação de interesse público e responsabilidade generalizada, colocam-se à frente de sua gestão as estruturas vinculadas à Administração Pública, embora outros segmentos também se envolvam, como instituições do mercado, religiosas, científicas e da sociedade civil. Há também o papel fundamental dos cidadãos que, como possíveis vítimas da doença, são cobrados por sua responsabilidade cívica e moral quanto às medidas de prevenção e controle da doença.

Dentro desse contexto de ações coletivas e individuais, vê-se a manifestação de tensões éticas, como nos conflitos motivados por: valores e objetivos diferenciados (Aung, Rahman, Nurumal, \& Ahayalimudin, 2017); informações limitadas e dispersas; múltiplas demandas; e escassez de recursos (Santos \& Serafim, 2020). Essas tensões levam a dilemas morais que surgem de maneira mais evidente, tornando o processo de decisão ética - aquela que pode beneficiar ou prejudicar outras pessoas (Santos, 2019) - ainda mais complexo. Podem, ademais, influenciar políticas públicas e ações governamentais na gestão da pandemia.

Como forma de contribuir ao debate sobre a resposta à crise do novo coronavírus, este short paper tem como objetivo identificar e debater alguns dos principais dilemas morais que desafiam a gestão pública brasileira no enfrentamento da pandemia. Entende-se que o debate ético na gestão pública não irá, necessariamente, indicar o caminho mais certo a se seguir; mas possibilitará raciocínios mais claros, além de moralmente justificáveis, no processo ético em tempos de crise.

\section{DILEMAS MORAIS E DECISÃO ÉTICA}

O dilema moral foi definido por Santos (2019, p. 52) como a “[...] vivência de uma tensão entre os possíveis caminhos de ação moral na busca pela melhor decisão em determinada circunstância, sendo a circunstância vista pela perspectiva daquele que interage com o dilema moral". Caracteriza-se por: “(a) ser uma situação complexa, (b) criada pelo conflito de múltiplas obrigações e/ou interesses - considerados certos - que poderiam ser exercidos isoladamente, (c) porém, em dado contexto, somente um curso de ação pode ser escolhido [...]" (p. 52). Dubnick e Justice (2006) consideram que o verdadeiro dilema para aqueles que ocupam funções públicas é a escolha entre o que se julga ser eticamente obrigatório 'aqui e agora' e a possibilidade de que a mesma decisão possa ser condenada em outro contexto.

Sendo assim, concorda-se com Waldo (2000) quando afirma que toda decisão que visa ao interesse público é inevitavelmente complexa, moralmente falando, independentemente de seu contexto. Também para Cooper (1998, p. 90), “[...] o conflito entre diferentes obrigações se configura como a forma mais típica pela qual os administradores públicos vivenciam os dilemas éticos". Entre os tipos mais comuns, o autor destaca: conflito entre interesses ou valores; conflitos entre fontes de autoridade; e conflito de papéis ou responsabilidades. 
Com o objetivo de auxiliar na análise de questões éticas, deixando as tensões mais visíveis para a tomada de decisão, Kidder (2007) elaborou quatro paradigmas de classificação de dilemas do tipo certo versus certo, quais sejam: justiça versus compaixão; curto prazo versus longo prazo; indivíduo versus comunidade; e verdade versus lealdade. Segundo o autor, "[...] esses quatro padrões nos ajudam a descrever as questões básicas no cerne de tantos conflitos éticos" (Kidder, 2007, p. 150).

Santos (2019) também diferencia o dilema moral em dois tipos: horizontal e vertical. No primeiro não há uma hierarquia ética clara de prioridades, isto é, não há um caminho evidente, o que pode ser visto por filósofos racionalistas como um dilema insolúvel. Entretanto, ao se tornarem reais, demandam soluções por parte dos tomadores de decisão. Nos dilemas verticais, a hierarquia ética é mais evidente dadas as circunstâncias legais e de autonomia moral para a decisão.

Como exemplo de dilema moral em um contexto de crise, French e Raymond (2009) relatam que, em 2002, funcionários de saúde de 46 diferentes estados dos Estados Unidos reuniram-se com a meta de determinar quais fatores eram de maior importância no caso de uma pandemia de gripe: redução de mortes, redução de doenças, limitação de impacto, garantia de serviços essenciais ou implementação da distribuição equitativa de vacina. Os participantes estavam divididos, mas deveriam decidir como equilibrar equitativamente o tratamento dos infectados e as medidas de quarentena com a necessidade de manter os serviços essenciais prestados pelos profissionais de saúde, prevenindo a propagação.

Esse exemplo poderia ser a realidade do que se vivencia com a pandemia do novo coronavírus, se não fosse pela diferença substancial de que, até maio de 2020, ainda não foi descoberta uma vacina que previna o organismo contra a COVID-19, tampouco como se dá seu tratamento de maneira efetiva, o que torna as decisões muito mais complexas e difíceis, reforçando a necessidade de reflexão e debate sobre as questões éticas enfrentadas durante esta crise. Santos (2019, p. 288) defende que “[...] o reconhecimento e a compreensão de dilemas morais podem dar pistas oportunas para o desenvolvimento de melhores práticas de gestão para as organizações públicas, auxiliando na análise de questões morais por mais de uma perspectiva e caminho de ação". Desse modo, também se espera um melhor e/ou mais seguro processo de gestão pública democrática e cidadã.

\section{PROCEDIMENTOS METODOLÓGICOS}

Tendo em vista o objetivo deste short paper, a intenção de tratar dos desafios concretos impostos pela pandemia e do tema, com sua complexidade, em debate, optou-se por uma abordagem qualitativa que alcançasse a essência dos dilemas morais reais da gestão pública brasileira. A técnica de coleta de dados constituiu-se de pesquisa documental de textos publicados em websites jornalísticos que apresentassem situações dilemáticas já ocorridas ou ainda em ocorrência no enfrentamento da pandemia no Brasil. Esses textos, além de trazerem uma diversidade de informações, possibilitaram acompanhar o histórico dos enredos dilemáticos selecionados para análise. Assim, percebeu-se a dimensão temporal dos fatos, bem como os indivíduos, grupos, comportamentos, mentalidades e práticas presentes na situação (Cellard, 2008).

Por meio de indicações sobre situações nas quais comumente encontram-se dilemas morais na literatura sobre ética na gestão de emergências (Aung et al., 2017; Geale, 2012; Santos \& Serafim, 2020), foram selecionados tópicos para a busca de casos da gestão pública brasileira: ações de triagem; fundos de socorro; comunicação de risco; auxílio de profissionais; alocação de recursos; diferenças linguísticas, religiosas e culturais; grupos vulneráveis; vigilância de doenças transmissíveis; e quarentena/isolamento. 
Com essas indicações, realizou-se a pesquisa sobre notícias relacionadas às temáticas dentro do contexto da pandemia e da gestão pública brasileira. Sua realização deu-se entre o período de 20 a 26 de abril de 2020 por meio de um portal eletrônico de buscas com as palavras: 'pandemia,' 'coronavírus', 'Brasil' e palavras que remetessem à Administração Pública, como 'governo', 'serviço público', 'saúde pública', 'Estado' e 'gestão pública'. Com os resultados localizados, foram selecionados aqueles que se adequassem ao conceito de dilema moral adotado neste trabalho e suas características fundamentais, quais sejam: ser uma situação complexa, criada pelo conflito de múltiplas obrigações que poderiam ser exercidas isoladamente, mas, em virtude do contexto da gestão da pandemia, somente um curso de ação pode ser adotado (Santos, 2019).

Para não se ater a somente uma descrição de acontecimentos, buscaram-se os casos de dilemas morais em mais de uma fonte, isto é, em mais de um website jornalístico. Dessa maneira, foram ampliadas as fontes de informações, indicações e esclarecimentos para elucidar os dilemas em debate (Figueiredo, 2007).

\section{DILEMAS MORAIS VIVENCIADOS NA RESPOSTA BRASILEIRA À PANDEMIA DO NOVO CORONAVÍRUS}

As situações identificadas como moralmente dilemáticas na resposta brasileira à pandemia do novo coronavírus são descritas nesta seção, juntamente com a perspectiva ética de cada uma delas. Seis áreas temáticas foram identificadas: isolamento social; uso de big data no gerenciamento da pandemia; atuação dos profissionais de saúde; auxílio emergencial federal e burocracia; suspensão de aulas e atividades educacionais presenciais; e liberação de presidiários como medida de prevenção.

\subsection{Isolamento social como medida de prevenção: necessidade, restrição de direitos e/ou responsabilidade cívica/moral}

Como uma das medidas de prevenção à propagação do novo coronavírus, a OMS recomenda o isolamento social a todos aqueles que podem ficar em casa, ou seja, não trabalham em serviços considerados essenciais. O estado de Santa Catarina foi o primeiro no Brasil a decretar quarentena, em 18 de março. Comércio, academias, templos e igrejas, transporte coletivo, parques e espaços públicos não eram permitidos. Medidas como essas foram tomadas de forma mais ou menos flexível em diversos outros estados brasileiros ou pelos próprios municípios.

Em 25 de março, o jornal $O$ Estado de S. Paulo identificou algum tipo de bloqueio em pelo menos 22 estados brasileiros. Não eram somente 'barreira sanitárias', mas também restrições que afetavam - ou ainda afetam - o direito de ir e vir (Gazeta do Povo, 2020), como no município de Porto Alegre, onde o prefeito emitiu decreto restringido a circulação de pessoas com mais de 60 anos, com multa em caso de descumprimento (GaúchaZH, 2020).

\section{Perspectiva ética}

A decisão pela adoção ou não de um isolamento social ou estado de quarentena traz inúmeras consequências para grande parcela da população. Enfrentando essas questões, gestores públicos e cidadãos colocam-se em dilemas morais de curto versus longo prazo e/ou de riscos versus benefícios em relação a perspectivas futuras (Kidder, 2007) diante da incerteza das consequências dessa medida. 
Relacionado ao isolamento social, há a discussão sobre a restrição do direito de ir e vir do cidadão versus a justificativa de saúde pública em tempos de crise. Assim, a gestão pública enfrenta o desafio de conciliar a liberdade individual dos cidadãos com a necessidade de diminuir a propagação do vírus. Rego et al. (2020b, p. 4) defendem que o "[...] isolamento pode e deve ser voluntário, salvo nos casos de pessoas já sabidamente contaminadas, pela possibilidade de prejudicar terceiros e ferir com isso a ética do respeito recíproco". Essa perspectiva ética também poderia ser chamada de ética do cuidado' ou 'ética das virtudes'. De acordo com essa filosofia moral, é importante que o indivíduo pretenda ser uma boa pessoa e se importe com os demais envolvidos de tal modo, que se coloque no lugar do outro (Kidder, 2007).

Do ponto de vista individual, o isolamento social pode ser visto como um ato de solidariedade, pois, nesse caso, levam-se em conta as consequências dos próprios atos tanto para si quanto para os demais. Ao cuidar de si, também se está cuidando do outro diretamente. Dessa maneira, ao indicar que as pessoas fiquem em casa o máximo possível, a OMS e os gestores públicos que concordam com essa medida de respeito recíproco compartilham-na com as pessoas ou transferem para elas a responsabilidade moral pela propagação ou não do novo coronavírus.

Contudo, mesmo com valores iguais, as pessoas têm necessidades diferentes. Então, como aqueles que precisam trabalhar diariamente para sobreviver ou aqueles que não têm água, luz e outras condições para o 'confinamento' conseguem passar 24 horas por dia dentro de casa? Assim, no caso de pessoas em situação de vulnerabilidade, medidas de isolamento social, quando impostas, não levam em consideração o contexto específico de cada realidade. Tornam a ação, desse modo, discriminatória, desigual e com uma perspectiva utilitária que coloca o fim da ação acima do bem próprio do agente individual.

\subsection{Big Data no gerenciamento da pandemia: 'big brother' ou ferramenta de gestão}

O rastreamento de telefones celulares virou uma ferramenta contra aglomerações e de combate à transmissão do novo coronavírus. Por meio desse monitoramento, autoridades podem tomar providências em tempo real para dispersar pessoas e orientá-las sobre os riscos da COVID-19. Entretanto, o monitoramento despertou reações de desconfiança em algumas pessoas que temem ter o direito de ir e vir infringidos pelos governantes, bem como seu direito à privacidade, assegurado em legislação (Barone \& Desideri, 2020). Segundo especialistas, nos moldes atuais, o sistema em desenvolvimento no Brasil não permite o acesso à identidade e ao número de telefone das pessoas que transitam pelas ruas com seus aparelhos celulares (Magenta, 2020).

\section{Perspectiva ética}

O debate ético sobre o uso de dados pessoais como ferramenta tecnológica para vigilância e redução de aglomerações é similar ao realizado sobre as medidas de isolamento social: até onde as medidas de interesse coletivo podem avançar ou influenciar o interesse individual? Para a gestão pública, em períodos de crise, esse dilema aparentemente classifica-se como do tipo vertical (Santos, 2019), uma vez que as convicções pessoais são minimizadas por um senso de responsabilidade pelo controle da pandemia. Portanto a tomada de decisão é facilitada em virtude das circunstâncias emergenciais e prioridades na hierarquia ética de decisões. 
De um ponto de vista utilitário, o direito à privacidade individual pode ser minimizado em razão de um benefício maior a um número maior de pessoas em uma crise de saúde pública. No entanto, essa medida - quando não autorizada individualmente - pode ser vista como um risco de instauração de um estado de vigilância permanente sobre as liberdades individuais e, talvez, de abertura de um caminho para outras ações de cerceamento da autonomia do cidadão.

Para tanto, no caso de adoção pública desse tipo de vigilância tendo como justificativa a pandemia do novo coronavírus, é importante considerar a dimensão ética temporal, uma vez que a questão legal já foi dada como superada. Segundo Drozenová (2016), no campo da ética em situações de crises, em determinados períodos (de tempo), alguns valores morais têm prioridade. Para o autor, essa questão não se trata de um relativismo moral, mas de necessidades que a circunstância da pandemia impõe aos gestores públicos.

Tal dimensão temporal e circunstancial é desconsiderada pela filosofia deontológica (Drozenová, 2016). Para aqueles que defendem essa perspectiva moral e/ou aqueles que são contra o uso de dados pessoais de forma não autorizada, mesmo com a justificativa da pandemia, o fim da ação - o propósito de utilização dos dados - não se justifica eticamente, uma vez que só as consequências previstas não fazem do meio utilizado uma ação boa (Treviño \& Nelson, 2010).

\subsection{Profissionais de saúde: honrar a profissão, proteger a família e a si próprio}

As equipes de saúde enfrentam difíceis dilemas durante o período da pandemia. Na luta contra o novo coronavírus, profissionais de todo o mundo têm sido infectados, alguns até vindo a óbito, mesmo com o uso de equipamentos de proteção - que já estão escassos em diversos países (BBC, 2020). Ao mesmo tempo que são essenciais neste momento, muitos deles também encontram-se dentro do grupo de risco da doença, como é o caso do médico R. B., que trabalha há 51 anos em um hospital público de São Paulo. Ao se encontrar afastado devido à sua idade, o médico comenta: "Mas fica uma situação chata. Somos em 30 colegas na minha equipe, eu sou o mais velho, mas muitos têm mais de 60. Se eu me coloquei na situação de médico ativo, eu não poderia recuar nessa hora" (Rossi, 2020).

Não só pelo risco de autoinfecção temem os profissionais que atuam na linha de frente do combate, eles também temem carregar consigo o próprio inimigo, vendo em si um vetor para a transmissão do vírus em sua própria casa (Carbone, 2020).

\section{Perspectiva ética}

Zack (2009) defende que, mesmo em situações de crise, os profissionais da linha de frente - da área de saúde, policiais, bombeiros, da limpeza urbana, entre outros - devem ser vistos como pessoas normais, com seus medos, incertezas e desafios, e não como 'super-heróis de ficção', inabaláveis. Eles também possuem família, casa, preocupações e podem ser - ou estar sendo - pessoalmente atingidos, ao mesmo tempo que se dedicam ao controle de um assunto de interesse público, como é o caso da pandemia. Nesse contexto, podem surgir dilemas morais de diversos tipos, como conflitos de papéis entre profissão versus vida pessoal; justiça versus compaixão; e entre as escolhas profissionais diante de recursos escassos, tal como: qual vida priorizar?

Independentemente do tipo de dilema envolvido, normalmente ele será intenso e doloroso (Kidder, 2007), devido aos diferentes compromissos e expectativas que se apresentam na atividade desses 
profissionais durante uma crise como a que estamos vivendo. Porém, ainda sob o ponto de vista dos profissionais, McEntire (2015) argumenta que eles reconhecem os perigos e conflitos inerentes ao seu trabalho, mas desenvolvem suas atividades independentemente disso e, muitas vezes, não param de trabalhar para cuidar de suas próprias necessidades pessoais. Ademais, as normas profissionais não precisam sempre corresponder aos valores e normas pessoais do profissional e vice-versa (Aung et al., 2017), como é o caso daqueles que, mesmo estando dentro do grupo de risco, consideram que seu dever moral é atuar ao lado de seus colegas de equipe.

Por fim, têm sido vistos relatos de dilemas morais que estão se intensificando na atividade profissional da área de saúde pública durante a pandemia: escolher qual vida priorizar quando não há equipamentos; carência de espaço ou profissionais para tratar de todos que necessitam. Cidades como Manaus, Fortaleza e São Paulo têm enfrentado essa situação com as pessoas que possuem sintomas da COVID-19 ou já foram diagnosticadas com a doença. Há de se ressaltar que, no caso da saúde pública brasileira, os recursos limitados já faziam parte da realidade de inúmeras cidades, intensificando-se ou ganhando maior visibilidade com a atual pandemia.

A 'triagem de guerra' que tem sido adotada em tempos de crise e as difíceis escolhas médicas indicam que o dilema pode ser caracterizado como genuíno e horizontal, ou seja, com opções de ação que fazem parte de um mesmo sistema moral - preservar vidas -, cuja hierarquia ética de prioridades, por vezes, não é clara ou é questionável (Santos, 2019).

\subsection{Auxílio emergencial: necessidade, burocratização e possibilidade de desvios}

O governo federal disponibilizou auxílio emergencial de $\mathrm{R} \$ 600,00$ como medida de redução dos impactos econômicos causados pela pandemia. O benefício é destinado a trabalhadores informais, autônomos, microempreendedores individuais e desempregados. Dentre os requisitos para o recebimento do auxílio, estão a regularidade cadastral do Cadastro de Pessoa Física (CPF) e o cadastro do cidadão em uma plataforma digital.

A regularização do CPF é realizada de forma online e gratuita pelo website da Receita Federal do Brasil (RFB). Entretanto, para os casos em que não seja possível via internet, $o$ atendimento é realizado presencialmente em uma das unidades da RFB. O auxílio financeiro àqueles que estavam impossibilitados de trabalhar tendo, como uma de suas causas, o isolamento social, acabou acarretando filas e aglomerações nas agências da Caixa Econômica e RFB de diferentes estados brasileiros (Receita Federal, 2020).

Desde 13 de abril, milhares de pessoas - incluindo idosos e gestantes - passam horas nas calçadas, às vezes durante toda a madrugada na fila, para conseguir atendimento. Como tentativa de remediar essa aglomeração, o Tribunal Regional Federal da $1^{\text {a }}$ região suspendeu a exigência de regularização do CPF. Entretanto, o governo recorreu da decisão com o objetivo de evitar fraudes e desvios no sistema, sendo então mantida a exigência de regularização (Dondossola, 2020). 


\title{
Perspectiva ética
}

\author{
É preciso respeitar a lei, quando for estritamente necessário; \\ é preciso ter flexibilidade, quando a dimensão humana prevalece.
}

(Freitag, 2005, p. 87)

Fortes et al. (2020) mencionam que o direito à renda deve ser interpretado não como um privilégio, mas como um compromisso incondicional de toda a sociedade com a subsistência de seus membros. Para tanto, são necessárias soluções que respondam a carências da população mais vulnerável. Nesse caso, também deve ser considerado o uso ou não de tecnologias digitais. Além disso, Villoria (2011) entende que a busca pela eficiência 'a todo custo' pode gerar tensões que envolvem elementos de legalidade e objetividade, também essenciais na gestão pública.

Entretanto, no caso em questão, partiu-se do pressuposto de que ocorreriam desvios ou fraudes no processamento do auxílio financeiro. Assim, utilizou-se a burocracia como um instrumento de caráter ético (Santos, 2019) para “[...] blindar os bens públicos” (Cordeiro, 2017, p. 864). Essa medida gera um conflito de papéis da própria postura da Administração Pública: a dimensão social esbarra no papel controlador.

Ao escrever sobre a liberação de recursos e dependência da burocracia, Peci (2020) destaca: "Cada dia de demora na entrega destes recursos aos seus destinatários legítimos implicará em moradores passando fome e necessidade básicas, empresas falidas, desempregados e, principalmente, vidas perdidas". Diante desse dilema, questiona-se para quem ou para que servem o aparato estatal e as ações públicas.

\subsection{Suspensão das aulas e atividades educacionais presenciais}

Como forma de evitar aglomerações e deslocamentos, em meados de março, aulas da rede pública e privada foram suspensas em todo o país. Para lidar com a situação, algumas instituições de ensino têm adotado a educação à distância. No entanto, nem todos os estudantes do país têm acesso a computadores e internet, para lhes permitir a continuidade satisfatória de seus estudos. Segundo pesquisa realizada em 2018 pelo Comitê Gestor da Internet no Brasil (CGI.br), 58\% dos domicílios brasileiros não têm acesso a computadores e 33\% não dispõem de internet, sendo o acesso ainda mais restrito nas classes mais baixas (Valadares, 2020).

Buscando alternativas para o cumprimento do ano letivo escolar, a Câmara de Vereadores de Florianópolis aprovou no dia 20 de abril um projeto de lei que autoriza o regime especial de atividades de aprendizagens não presenciais para a educação básica municipal. Segundo a Secretaria de Educação do município, as crianças que não têm acesso à internet recebem materiais impressos entregues pelas próprias escolas $(\mathrm{G} 1,2020)$. Decisões similares têm sido tomadas ou cogitadas em escolas e universidades municipais, estaduais e federais do Brasil, para evitar a perda do ano ou semestre letivo, evasão escolar, diminuição do rendimento acadêmico, dentre outros impactos.

Mesmo com as suspensões das aulas e indecisões sobre a retomada presencial ou à distância, exigências legais, compromissos firmados e eventos específicos são mantidos, como foi a proposta do governo federal de realizar o Exame Nacional do Ensino Médio (ENEM) na mesma data programada antes do início da pandemia (Saldaña, 2020). Contudo, após diversas manifestações contrárias e ajuizamento de ação cível pública da Defensoria Pública da União (DPU), o Ministério da Educação decidiu pelo adiamento da aplicação do exame (Lesme, 2020). Há também a situação das instituições particulares que podem ter seus contratos interrompidos e/ou mensalidades escolares não pagas no caso de não cumprimento das atividades educacionais, levando a possíveis demissões e prejuízos financeiros.

REVISta de Administração Pública | Rio de Janeiro 54(4):909-922, jul. - ago. 2020 


\section{Perspectiva ética}

Os dilemas morais diante da suspensão das aulas presenciais em todo o Brasil e da adoção de outras estratégias de ensino têm como origem e fundamento questões legais, educacionais e sociais. Como continuar garantindo o direito de aprendizagem - e qualidade - sem considerar a situação de desigualdade educacional e social do país? Ademais, como desconsiderar os problemas que acarretam a não manutenção do ensino aos estudantes em isolamento social?

Embora a Lei de Diretrizes e Bases (LDB) disponha que o calendário escolar deverá adequar-se às peculiaridades circunstanciais, as dificuldades enfrentadas são muitas: famílias que não possuem orientação ou tecnologia para a educação em casa; impactos financeiros; ajustes operacionais; e questões trabalhistas. Essas dificuldades são apresentadas pelo Conselho Nacional de Educação (CNE, 2020) como justificativas para a adoção de atividades não presenciais capazes de permitir o encerramento do atual ano letivo ainda em 2020.

Tais iniciativas apresentam uma lógica ética instrumental de maximização de recursos e produtivismo que pode desconsiderar perdas importantes do processo ensino-aprendizagem, como a formação humana dos estudantes; a participação de profissionais preparados; a complexidade do trabalho educativo. Impõe-se, desse modo, um dilema moral de curto versus longo prazo (Kidder, 2007). Nesse caso, qualquer dos caminhos adotados trará impactos aos estudantes e às instituições educacionais, seja agora na manutenção do sistema educacional, ou futuramente nos resultados da formação dos alunos.

Há também um dilema do tipo 'nós versus eles' quando se considera que instituições particulares iniciaram antes das instituições públicas as ações de ensino remoto; ou que parcela significativa dos alunos de instituições públicas não dispõe de computador ou acesso à internet, enquanto outros colegas o possuem e poderão dar continuidade aos estudos, mesmo quando 'a linha de chegada' será a mesma, como a prova do ENEM.

Ainda do ponto de vista ético, Zack (2009) afirma que, em situações de crise, a ética utilitarista é a mais frequentemente aplicada, seguindo o princípio da Administração Pública da eficiência. Segundo essa filosofia moral, adota-se como critério de ação aquele que atinja o maior número de pessoas possível, considerando a limitação de recursos ou possibilidade de atendimento a todos.

\subsection{Liberação de presidiários como medida de contenção da pandemia}

O sistema penitenciário brasileiro conta com aproximadamente 752 mil detentos, além de 83 mil servidores (Adler, 2020). Como uma das medidas governamentais para conter a pandemia nesse ambiente, o Conselho Nacional de Justiça (CNJ) publicou a Recomendação 62/2020 referente à soltura de presos cuja liberdade provisória tenha sido condicionada ao pagamento de fiança e à transferência de detentos a outros regimes - como o domiciliar -, sobretudo no caso de gestantes, lactantes, idosos e presos provisórios encarcerados há mais de 90 dias (Conselho Nacional de Justiça [CNJ], 2020).

A justificativa para tal recomendação baseia-se no quadro de precariedade do sistema carcerário, com riscos graves de disseminação da COVID-19. Diante dessa recomendação, juízes tiveram a difícil decisão de manter pessoas presas, assumindo o risco de contaminação generalizada, ou soltar uma parte significativa dos presos, contrariando o sistema punitivista dominante (Mello, 2020). 
Ao se pronunciar sobre a situação, o ex-ministro da Justiça e Segurança Pública, Sergio Moro, defendeu que "[...] não podemos, a pretexto de proteger a população prisional, vulnerar excessivamente a população que está fora das prisões” (David, 2020, s.p.).

\section{Perspectiva ética}

Nesse tipo de dilema moral, os prisioneiros podem ser vistos como um público com vulnerabilidades diante das possibilidades de prevenção à contaminação do novo coronavírus, o que se torna uma questão ética uma vez que se considere que não possuem condições iguais de acesso a recursos de saneamento - assim como outras parcelas da população que também não os possuem -, em comparação àqueles cidadãos que estão livres.

Há também um conflito moral de autoridade e responsabilidades objetivas (Cooper, 1998) frente à recomendação do CNJ. Ambas as questões de 'saúde' versus 'justiça' possuem argumentos legais e morais para serem adotadas. Da mesma maneira, as consequências dos dois caminhos de ação são compartilhadas com a sociedade. Ao liberar presos segundo as recomendações do CNJ, a comunidade carcerária e o sistema público de saúde são beneficiados com a prevenção do surgimento de novos casos da doença. Ao mesmo tempo, a 'população livre’ também encontra-se vulnerável à reincidência de crimes e violência. Ademais, considerando esse cenário, a decisão ética esteve não somente em 'liberar ou não' parte dos presidiários, mas em saber quais seriam os limites dessa liberação - ou ajuda - e quando determinar eticamente quando acabar com ela (Burke, 2001).

\section{CONCLUSÕES}

Com base nas notícias sobre a pandemia no Brasil, este short paper identificou e debateu alguns dos principais dilemas morais enfrentados pela gestão pública brasileira nas ações de prevenção e combate à COVID-19. Os comentários aqui apresentados não dizem respeito a uma análise legalística sobre a gestão da crise; mas a um debate com possíveis olhares éticos sobre a questão, por meio de diferentes teorias morais. Nesse sentido, foi compartilhada a visão de Rego et al. (2020a, p. 1) quando afirmam que as "[...] implicações morais [da pandemia] tendo como contexto a realidade brasileira é, para nós, um convite à reflexão".

Foi possível perceber que, em contextos de crise, cidadãos e gestores públicos são deslocados de seu status quo, o que leva ao desenvolvimento de novas formas de percepção e raciocínio moral para problemas públicos já existentes que a pandemia evidenciou e novos desafios que as organizações públicas passaram a enfrentar. Portanto continuam necessárias as reflexões sobre os aspectos éticos da pandemia, destacando-se as obrigações sociais dos governos em relação aos seus cidadãos e aos profissionais essenciais ao seu combate, e os limites da interferência da autonomia e liberdade individual de cada um, principalmente quando inseridos em um contexto de crise.

Ressalta-se que não era objetivo esgotar os dilemas morais existentes, até porque eles são diversos e vão continuar surgindo, mas discutir alguns que parecem ser mais conhecidos e complexos até então. Todavia uma importante questão ética não foi incluída: a apresentação de 'economia versus saúde' como um dilema moral existente na pandemia. Faz-se necessária uma justificativa.

Visto que a crise impacta também a economia, líderes estão sugerindo, segundo uma perspectiva moralmente utilitária, que algumas pessoas devem morrer para que muitas outras possam viver 
(Gak, 2020), evitando assim uma crise econômica. Contudo essa equação representa um falso dilema moral para a Administração Pública, uma vez que se assume que: (1) a vida é um princípio e direito fundamental constitucionalmente resguardado, (2) a economia só existe porque há vida e um espaço de interesse comum (Lisboa, 2018), e (3) a Administração Pública tem a obrigação moral de criar mecanismos para que os cidadãos tenham saúde, segurança e integridade. Os líderes públicos são os responsáveis morais por tomar decisões legítimas para evitar que os cidadãos encontrem-se em um conflito entre 'vida-economia versus vida-saúde', provendo recursos aos necessitados, organizando a economia e o sistema público de saúde (Fortes et al., 2020). Sendo assim, economia e saúde representam, guardadas as devidas proporções, vidas humanas; consequentemente, não podem ser consideradas como irreconciliáveis - característica básica de um dilema moral - dentro de um mesmo contexto ético real.

Acredita-se que o debate ético realizado neste artigo, à luz da Filosofia, pode auxiliar a compreender e até mesmo questionar os enunciados que nos são dados em diferentes áreas do conhecimento, como a Administração Pública (Zappellini, 2013). Para tanto, são necessárias reflexões e debates sobre a vida real - como a pandemia do novo coronavírus em 2020 - e que evidenciam as questões éticas de interesse público diante das quais se espera que os gestores públicos tomem decisões acertadas, rápidas e cientes de suas consequências em relação a todas as parcelas da população, ainda que em um contexto de escassez de recursos e informações. Tendo-se consciência dos dilemas envolvidos entre eles os dilemas morais -, a gestão pode contar com um sistema de ferramentas e reflexões para melhor enfrentar tais situações (Puiu, 2015). 


\section{REFERÊNCIAS}

Adler, M. (2020, 31 de março). Coronavírus: Moro descarta soltura de presos em massa e nega casos confirmados no sistema. Estado de Minas (Nacional). Recuperado de https://www.em.com.br/app/noticia/ nacional/2020/03/31/interna_nacional,1134355/ coronavirus-moro-descarta-soltura-de-presos-emmassa.shtml

Aung, K. T., Rahman, N., Nurumal, M. S., \& Ahayalimudin, N. (2017). Ethical Disaster or Natural Disaster? Importance of Ethical Issue in Disaster Management. Journal of Nursing and Health Science, 6(2), 90-93.

BBC. (2020, 1 de abril). Coronavírus: por que a covid-19 afeta tanto os profissionais de saúde? (News - Brasil). Recuperado de https://www.bbc.com/ portuguese/internacional-52119508

Barone, I., \& Desideri, L. (2020, 12 de abril). Estados usam dados de celulares para monitorar aglomerações. Eles podem fazer isso? Gazeta do Povo (Vida e Cidadania). Recuperado de https:// www.gazetadopovo.com.br/vida-e-cidadania/ monitoramento-celulares-aglomeracoes-covid-19/

Burke, J. (2001). Administrative Ethics and Democratic Theory. In T. L. Cooper (Ed.), Handbook of Administrative Ethics (2nd ed. rev. and exp., pp. 603-622), New York, NY: Marcel Dekker.

Carbone, B. L. (2020). O dilema médico: levando o inimigo para a própria casa. Sanarmed (Colunistas). Recuperado de https://www.sanarmed.com/odilema-medico-levando-o-inimigo-para-a-propriacasa-colunistas

Cellard, A. (2008). A análise documental. In J. Poupart. A pesquisa qualitativa: enfoques epistemológicos e metodológicos (pp. 295-316). Petrópolis, RJ: Vozes.

Conselho Nacional de Educação. (2020). Proposta de parecer sobre reorganização dos calendários escolares e realização de atividades pedagógicas não presenciais durante o período de pandemia da Covid-19. Recuperado de http://portal.mec.gov.br/ index.php? option=com_docman \&view=downloa d\&alias=144511-texto-referencia-reorganizacaodos-calendarios-escolares-pandemia-da-covid19\&category_slug=marco-2020-pdf\&Itemid=30192
Conselho Nacional de Justiça. (2020, 17 de março). Recomendação N. 62, de 17 de março de 2020. Recomenda aos Tribunais e magistrados a adoção de medidas preventivas à propagação da infecção pelo novo coronavírus - Covid-19 no âmbito dos sistemas de justiça penal e socioeducativo. Recuperado de https://www. cnj.jus.br/wp-content/uploads/2020/03/62Recomenda\%C3\%A7\%C3\%A3o.pdf

Cooper, T. L. (1998). The Responsible Administrator: an Approach to Ethics for the Administrative Role. 4th ed. São Francisco, CA: Jossey-Bass.

Cordeiro, W. M. (2017). Burocracia na construção da Administração Pública do século XXI: uma reflexão teórica. In: Anais do $4^{\circ}$ Encontro Brasileiro de Administração Pública (pp. 801- 834), João Pessoa, $\mathrm{PB}$, Brasil.

David, A. (2020, 24 de março). Coronavírus e a imediata soltura de presos: uma questão de direitos humanos. Brasil de Fato (Início - Opinião). Recuperado de https://www.brasildefato.com. br/2020/03/24/artigo-coronavirus-e-a-imediatasoltura-de-presos-uma-questao-de-direitoshumanos

Dondossola, E. (2020, 22 de abril). 'Humilhante', diz grávida após passar a noite em fila de agência da Receita Federal no Rio. G1 (Bom Dia Rio). Recuperado de https://g1.globo.com/rj/ rio-de-janeiro/noticia/2020/04/22/humilhantediz-gravida-apos-passar-a-noite-em-fila-deagencia-da-receita-federal-no-rio.ghtml

Drozenová, W. (2016). Challenge of time as a moral imperative. Human Affairs, 26(1), 80-89.

Dubnick, M. J., \& Justice, J. B. (2006). Accountability and the Evil of Administrative Ethics. Administration \& Society, 38(2), 236-267.

Figueiredo, N. M. A. (2007). Método e metodologia na pesquisa científica (2a ed.). São Caetano do Sul, São Paulo, SP: Yendis Editora.

Fortes et al. (2020). O direito à renda básica no Brasil em tempos de Covid-19. Recuperado de https://www. arca.fiocruz.br/handle/icict/40786

Freitag, B. (2005). Ética na administração pública. Revista do Serviço Público, 56(1), 85-94. 
French, P., \& Raymond, E. (2009). Pandemic Influenza planning: an extraordinary ethical dilemma for local government officials. Public Administration Review, 69(5), 823-830.

Gak, M. (2020). Opinion: Economy vs. human life is not a moral dilemma. Recuperado de https://www. dw.com/en/opinion-economy-vs-human-life-isnot-a-moral-dilemma/a-52942552

GaúchaZH. (2020, 24 de março). Ministério Público questiona medidas que atingem o direito de ir e vir do cidadão. Recuperado de https:// gauchazh.clicrbs.com.br/coronavirus-servico/ noticia/2020/03/ministerio-publico-questionamedidas-que-atingem-o-direito-de-ir-e-vir-docidadao-ck865o2ht07bj01pqdreegmv0.html

Gazeta do Povo. (2020, 29 de março). Os bloqueios contra o coronavirus e o direito de ir e vir (Editorial Opinião). Recuperado de https://www.gazetadopovo. com.br/opiniao/editoriais/bloqueios-coronavirusdireito-de-ir-e-vir/

Geale, S. K. (2012). The ethics of disaster management. Disaster Prevention and Management, 21(4), 445-462.

G1. (2020, 21 de abril). Com aulas suspensas, Câmara de Florianópolis aprova projeto para atividades online na rede municipal. Recuperado de https://g1.globo. $\mathrm{com} / \mathrm{sc} /$ santa-catarina/noticia/2020/04/21/comaulas-suspensas-camara-de-florianopolis-aprovaprojeto-para-atividades-online-na-rede-municipal. ghtml

Kidder, R. M. (2007). Como tomar decisões difíceis: muitas vezes na vida você precisa escolher entre o certo e o certo. São Paulo, SP: Gente.

Lesme, A. (2020, 18 de abril). Justiça determina alteração do cronograma do Enem 2020 e mudanças são anunciadas. Brasil Escola (Notícias). Recuperado de https://vestibular.brasilescola.uol.com.br/enem/ justica-determina-alteracao-do-cronograma-doenem-2020-e-mudancas-sao-anunciadas/347735. html

Lisboa, A. M. (2018). Economia política aristotélica: cuidando da casa, cuidando do comum. Logeion: Filosofia da informação, 4(1), 36-72.

Magenta, M. (2020, 3 de abril). Coronavírus: governo brasileiro vai monitorar celulares para conter pandemia. Terra Networks Brasil S.A (Notícias). Recuperado de https://www.terra.com.br/noticias/ coronavirus/coronavirus-governo-brasileiro-vaimonitorar-celulares-para-conter-pandemia,62ec11 0da1579b3ae5eb3971b82966b6k0liy3ms.html

McEntire, D. A. (2015). Disaster Response and Recovery: Strategies and Tactics for Resilience. Hoboken, NJ: Wiley.

Mello, I. (2020, 28 de março). Coronavírus: Gilmar Mendes mantém recomendação do CNJ por soltura de presos. UOL (Notícias - Política). Recuperado de https://noticias.uol.com.br/politica/ ultimas-noticias/2020/03/28/coronavirus-gilmarmendes-mantem-recomendacao-do-cnj-porsoltura-de-presos.htm

Ministério da Saúde do Brasil. (2020). Painel Coronavírus. Recuperado de https://covid.saude. gov.br/

Peci, A. (2020). Os recursos foram liberados: é preciso liberar e mobilizar a burocracia. Recuperado de https://portal.fgv.br/artigos/recursos-foramliberados-e-preciso-liberar-e-mobilizar-burocracia

Puiu, S. (2015). Ethical Dilemmas in the Public Sector. Management \& Marketing Journal, 13(1), 57-62.

Receita Federal. Ministério da Economia. (2020, 08 de abril). Nota de esclarecimento sobre regularização do CPF para recebimento de auxílio emergencial de $R \$$ 600,00 para trabalhadores informais, desempregados, MEIs e contribuintes individuais do INSS. Recuperado de https://receita.economia.gov.br/noticias/ ascom/2020/abril/nota-de-esclarecimento-sobreregularizacao-do-cpf-para-recebimento-de-auxilioemergencial-de-r-600-00-para-trabalhadoresinformais-desempregados-meis-e-contribuintesindividuais-do-inss

Rego, S., Palácios, M., Fortes, P. D., Schramm, F. R., Costa, A., Brito, L., ... Gomes, A. P. (2020a). Existe o dever de falar a verdade no contexto da Covid-19? Recuperado de http://www.ensp.fiocruz.br/portalensp/informe/site/materia/detalhe/48745

Rego, S., Fortes, P., Barboza, H. H., Borges, L., Brito, L., Costa, A., ... Tome, B. (2020b). Existe o direito de dizer não no contexto da Pandemia Covid-19? Recuperado de https://www.researchgate.net/ publication/340875304_Existe_o_direito_de_dizer_ nao_no_contexto_da_Pandemia_Covid-19

Rossi, M. (2020, 25 de março). "Eu não poderia recuar nessa hora": o dilema dos profissionais da saúde que estão no grupo de risco. El País 
(Brasil). Recuperado de https://brasil.elpais.com/ brasil/2020-03-25/eu-nao-poderia-recuar-nessahora-o-dilema-dos-profissionais-da-saude-queestao-no-grupo-de-risco.html

Saldaña, P. (2020, 16 de abril). Com Enem mantido, MPF quer que MEC mostre ações para assegurar ensino na pandemia. Folha de São Paulo (Educação). Recuperado de https://www1.folha.uol.com.br/ educacao/2020/04/com-enem-mantido-mpf-quermec-mostre-acoes-para-assegurar-ensino-napandemia.shtml

Santos, L. S. (2019). A ética da gestão pública à luz da abordagem da racionalidade: os dilemas morais vivenciados na gestão de riscos e desastres em Santa Catarina. (Tese de Doutorado). Universidade do Estado de Santa Catarina, Florianópolis, Brasil.

Santos, L. S., \& Serafim, M. C. (2020). Quando o Desastre Bate à Porta: Reflexões sobre a Ética da Gestão Pública de Riscos e de Desastres. Administração Pública e Gestão Social, 12(2), 1-16.

Treviño, L. K., \& Nelson, K. A. (2010). Managing Business Ethics: Straight Talk About How To Do It Right. New York: John Wiley.
Valadares, M. (2020, 23 de março). Coronavírus faz educação a distância esbarrar no desafio do acesso à internet e da inexperiência dos alunos. G1 (Educação). Recuperado de https://g1.globo. com/educacao/noticia/2020/03/23/coronavirusfaz-educacao-a-distancia-esbarrar-no-desafio-doacesso-a-internet-e-da-inexperiencia-dos-alunos. ghtml

Villoria, M. (2011). Ética en el sector público: una reflexión desde la ética aplicada. Encuentros Multidisciplinares, 13(39), 19-28.

Waldo, D. (2000). Public Administration and Ethics: a Prologue to a Preface. In Stillman, R. J. (Ed.). Public Administration: Concepts and Cases (7th ed., pp. 472482). Boston, USA: Houghton Mifflin.

Zack, N. (2009). Ethics for Disaster. Lanham, MD: Rowman \& Littlefield.

Zappellini, M. B. (2013). Ética e Administração Pública: uma Abordagem a partir de três Modelos Normativos. In Anais do $37^{\circ}$ Encontro da Associação Nacional de Programas de Pós-graduação em Administração, Rio de Janeiro, RJ, Brasil.

\section{Laís Silveira Santos}

https://orcid.org/0000-0002-4737-5470

Doutora em Administração pela Universidade do Estado de Santa Catarina (ESAG/UDESC); Administradora na Universidade Federal de Santa Catarina (UFSC); Pesquisadora do Grupo de Pesquisa AdmEthics - Ética, Virtudes e Dilemas Morais na Administração. E-mail: lais.ssantos@yahoo.com.br 